\title{
Intercompany meeting of the health professions
}

\author{
V Piraino \\ From de Senectute: Age and Health Forum \\ Catanzaro, Italy. 5-7 December 2009
}

The rehabilitation, within the whole culture of disability, is configured as the central moment of doing rehabilitation which is related to the activity of the "person" in its entirety and complexity. The concept of " quality of care" reported the citizen at the center of interest of operators called to play a practice increasingly effective, timely, continuous, secure, appropriate (respecting the centrality of the assisted).

The theme of neurological diseases, which affect the adult compromising important functions for the quality of life, is a field of great interest for the speech- therapy clinic, amplified in recent years by epidemiological data and incidence of disease responsible for these deficits. "Aging isn't in itself a disease": today the elderly independent people unable to manage themselves play meaningful social rules. In Europe, in all nation as well as in our region, taking in the challenge of the aging well, mean especially invest in preventive health policies. Unfortunately though this seems an established fact, seems that this situation is not addressed in a constructive manner.

Estimate that the percentage of population over 65 age of years, will reach $34,4 \%$ in 2050 . Those over 80 should reach $14.2 \%$ compared to $4.3 \%$ today. This sort of demographic revolution reinforces the right the right to health enshrined by the Constitution and meanwhile infuses law the duty to sustain it over time. The lengthening of life expectancy should be evaluated with optimist although parallel will increase the absolute number of people with severe limitations. Therefore are indispensable various preventive and curative interventions that society will impose. Seems clear that this situation must be addressed and monitored for resource planning and supply of care services, employees in large part of health systems' budgets, often intended to contain and rationalize the expenditure.

\footnotetext{
The health professions in Calabria and the elderly patient Speech therapist -
} Operating Unit of Rehabilitation ( Lamezia Terme ) A.s.p. of Catanzaro, Italy
In the field of neurological diseases of the adults, unfortunately are reported dramatic expectations in the answer of taken charge, particularly in our region, the most disadvantaged, where there is the phenomenon of migration. In an alarming situation, there are, however, important experiences and centers of excellence also qualified by the virtuosity of many professionals who collaborate in teams rehabilitation, quickly operational, with involvement also of users' associations.

Agency professional in carrying out the activities of its sole responsibility to be seen in a perspective of collaboration with other professional, in a total commitment to the political, civil, scientific sphere raises uniting the provision of public services and the guarantee systems for users.

Published: 19 May 2010

doi:10.1186/1471-2318-10-S1-L79

Cite this article as: Piraino: Intercompany meeting of the health professions. BMC Geriatrics 2010 10(Suppl 1):L79.

Submit your next manuscript to BioMed Central and take full advantage of:

- Convenient online submission

- Thorough peer review

- No space constraints or color figure charges

- Immediate publication on acceptance

- Inclusion in PubMed, CAS, Scopus and Google Scholar

- Research which is freely available for redistribution

Submit your manuscript at www biomedcentral.com/submit 